Article

\title{
An Improved Method to Encapsulate Laccase from Trametes versicolor with Enhanced Stability and Catalytic Activity
}

\author{
Sitong Zhang ${ }^{1,+}$, Zhuofu Wu ${ }^{1,+} \mathbb{D}^{\mathbb{D}}$, Guang Chen ${ }^{1, *}$ and Zhi Wang ${ }^{2, *}$ \\ 1 College of Life Science, Jilin Agricultural University, Changchun 130118, China; \\ sitongzhang9@163.com (S.Z.); wzf@jlau.edu.cn (Z.W.) \\ 2 Key Laboratory of Molecular Enzymology and Engineering of Ministry of Education, College of Life Science, \\ Jilin University, Changchun 130012, China \\ * Correspondence: guangc61@gmail.com (G.C.); wangzhi@jlu.edu.cn (Z.W.); Tel.: +86-431-8453-2942 (G.C.); \\ +86-431-8518-2281 (Z.W.) \\ + These authors contributed equally to this work.
}

Received: 14 June 2018; Accepted: 12 July 2018; Published: 17 July 2018

check for updates

\begin{abstract}
In this work, laccase from Trametes versicolor pretreated with copper ion solution was entrapped in copper alginate beads. The presence of laccase in copper alginate beads was verified by Fourier transform infrared (FTIR) spectroscopy. The alginate concentration used was optimized based on the specific activity and immobilization yield. After entrapment, laccase presents perfect $\mathrm{pH}$ stability and thermal stability with 2,2'-azinobis-(3-ethylbenzthiazoline-6-sulphonate) (ABTS) as the substrate. Moreover, laccase in copper alginate beads exhibits good reusability during continuous batch operation for removing 2,4-dichlorophenol. More importantly, owing to the coupled effect of copper ion activation and copper alginate entrapment, the entrapped laccase shows a 3.0-fold and a 2.4-fold increase in specific activity and 2,4-DCP degradation rate compared with that of free laccase, respectively.
\end{abstract}

Keywords: laccase; copper alginate; entrapment; specific activity; degradation rate

\section{Introduction}

Laccase can catalyze the oxidation of a variety of aromatic compounds (preferably phenolic compounds) [1,2] and has been widely employed for delignification, plant fiber derivatization, textile dye or stain bleaching, and contaminated water or soil detoxification [3-6]. However, the industrial applications of laccase are still seriously limited owing to their poor stability and high cost [7]. It is well known that these limitations can be overcome by immobilization technology [8-12]. In earlier studies, Rogalski et al. immobilized laccase on controlled porosity glass and measured its activity in the aqueous solution containing organic solvents [13]. Dodor et al. fixed the laccase on the kaolinite by the glutaraldehyde method and they demonstrated that the temperature stability, $\mathrm{pH}$ stability, and storage stability of immobilized laccase was improved as compared with the free laccase [14]. Hwang et al. immobilized laccase on nanoparticles and kaolinite via the physical adsorption or chemical covalence method and they found that immobilized laccase could act as an efficient tool to oxidize BaP [15]. In recent years, Pellis et al. prepared the immobilized laccase using Accurel MP1000 beads as a carrier to facilitate the oxidation of Kraft lignin (KL) and lignosulfonate (LS) [16]. Greimel et al. used immobilized laccase to remove morphine and complete morphine elimination was achieved within 30 min [17].

As a natural polysaccharide extracted from brown seaweeds, alginate has been commonly used for immobilization of laccase in the form of calcium alginate beads $[18,19]$. It is known that the activity 
of laccase in the solution can be enhanced by the addition of $\mathrm{Cu}^{2+}$ ions [18] and that copper has a greater affinity for alginate than calcium during the gelation of alginate beads [20]. Thus, the copper alginate beads may be a better support for laccase immobilization because of the activation effect of $\mathrm{Cu}^{2+}$ ions and high affinity between the alginate and $\mathrm{Cu}^{2+}$ ions [21]. Several teams had used copper alginate beads as carrier to entrap the laccase and found that the operation stability and reusability of entrapped laccase were significantly improved [22,23]. However, the specific activity of laccase in these studies declines. In their reports, the copper alginate entrapment was accomplished by allowing the droplets of Na-alginate solution containing laccase to fall into the $\mathrm{Cu}^{2+}$ solution. The high viscosity of Na-alginate solution containing laccase might limit the activation effect of $\mathrm{Cu}^{2+}$ and then result in the low laccase activity.

Thus, in this study, laccase was dissolved in a $\mathrm{Cu}^{2+}$ solution before entrapment to enhance its activity. Then the activated laccase was entrapped into copper alginate beads by dropping the sodium alginate solution into the $\mathrm{Cu}^{2+}$-laccase solution. The specific activities of entrapped laccase produced by different entrapment protocols were measured and the concentrations of sodium alginate solution were screened based on laccase's immobilization yield and specific activity. The Fourier transform infrared (FTIR) spectrum of entrapped laccase was characterized. Subsequently, the $\mathrm{pH}$ stability and thermal stability of entrapped laccase was investigated. Finally, the entrapped laccase was used to degrade 2,4-dichlorophenol (2,4-DCP) to evaluate its potential value in the treatment of phenol wastewater. Entrapped laccase reusability was also investigated.

\section{Results}

\subsection{The Effect of Immobilization Protocols}

In general, the geometry of an enzyme active site can be perturbed by ligands, such as the substrate, substrate analogues, or other components (salts and polymer), and the induced conformation can be subsequently frozen by the corresponding immobilization processes [24]. Herein, the different protocols for entrapment of laccase were performed to demonstrate whether the favorable conformers of laccase activated by $\mathrm{Cu}^{2+}$ ions could be retained by copper alginate entrapment. From Table 1, the specific activity of entrapped laccase produced by protocol II, III, and IV was lower than that of the free laccase, which is attributed to the mass transfer limitation of the substrate and product in the alginate beads. Moreover, given that copper has greater affinity for alginate than calcium during alginate gelation, some of the laccase active site $\mathrm{Cu}^{2+}$ ions may have been extracted during gelation in the presence of $\mathrm{CaCl}_{2}$, leading to the lower specific activity of entrapped laccase produced by protocol III and IV as compared with the free laccase. As compared with the free laccase, the lower specific activity of the entrapped laccase produced by protocol II illustrates that the $\mathrm{Cu}^{2+}$ ions incorporated in the net of $\mathrm{Cu}$-alginate beads cannot activate laccase. The poor specific activities of entrapped laccase produced by protocol III and IV also indicate that $\mathrm{Ca}^{2+}$ ions incorporated in the net of Ca-alginate beads and $\mathrm{Ca}^{2+}$ ions in solution cannot improve the specific activity of laccase. The experimental data verified that the specific activity of free laccase is increased by a factor of 2.3 with the addition of $0.8 \mathrm{mM} \mathrm{CuCl}_{2}$, suggesting that some of active-site $\mathrm{Cu}^{2+}$ ions in laccase may have been removed during purification and/or dialysis. In contrast, the entrapped laccase produced by protocol I shows a 3.0-fold increase in specific activity compared to that of the free one. Most importantly, the entrapped laccase produced by protocol I shows a 1.3-times increase in specific activity as compared with free laccase supplemented with $\mathrm{CuCl}_{2}$. The enhanced specific activity of entrapped laccase may be attributed to the coupled effect of $\mathrm{Cu}^{2+}$ ions activation and copper alginate entrapment. Since the $\mathrm{Cu}^{2+}$ ion is a component of the active site of laccase [6], laccase can give more active conformation in $\mathrm{CuCl}_{2}$ solution. The active conformation of laccase induced by $\mathrm{CuCl}_{2}$ solution can be frozen by copper alginate entrapment to some extent. As a result, the entrapped laccase shows enhanced specific activity. In Roberto's review, immobilization technology may become a tool to "freeze" the more active conformation of the enzyme [25], which is in agreement with our results. We speculated that induced active conformers of laccase in copper 
alginate beads may be retained and enriched owing to the hypothesis of macromolecular crowding and confinement $[26,27]$. There are some other reports focusing on improving enzymatic activity via the allosteric effect regulated by metal ions in the carrier [28,29], which may be another reasonable explanation for our results. The entrapment parameters involved in protocol I were optimized in the following study.

Table 1. The specific activity of entrapped laccase with different protocols.

\begin{tabular}{cc}
\hline Samples & Specific Activity $(\mu \mathrm{mol} / \mathrm{mg} / \mathrm{min})$ \\
\hline Protocol I & $659.1 \pm 16.4$ \\
Protocol II & $119.4 \pm 18.3$ \\
Protocol III & $88.9 \pm 15.5$ \\
Protocol IV & $82.5 \pm 12.9$ \\
Free laccase & $217.0 \pm 11.2$ \\
Free laccase [a] & $499.1 \pm 17.5$ \\
\hline
\end{tabular}

[a] ABTS assay system contained $0.8 \mathrm{mM} \mathrm{CuCl}_{2}$.

\subsection{FTIR}

For verifying the presence of laccase in the copper alginate beads, the copper alginate beads, laccase, and the copper alginate beads loaded with laccase were characterized using FTIR spectroscopy. In Figure 1a, the peak at $816 \mathrm{~cm}^{-1}$ was observed. It is known that the peak at $816 \mathrm{~cm}^{-1}$ is assigned to vibrations of mannuronic acid residues in copper alginate beads [30]. In Figure 1b, the peaks at $1648 \mathrm{~cm}^{-1}$ and $1544 \mathrm{~cm}^{-1}$ are shown. These peaks ascribed to the vibrations of the amide I and II bands of protein [31]. The amide I band at $1648 \mathrm{~cm}^{-1}$ is mainly attributed to the contribution of $\mathrm{C}=\mathrm{O}$ stretching vibrations of the amide groups in protein; the amide II at $1544 \mathrm{~cm}^{-1}$ derives mainly from in-plane $\mathrm{NH}$ bending vibration and $\mathrm{CN}$ stretching vibration in protein [32]. After entrapment, all these characteristic bands for both laccase and copper alginate beads can be found in Figure 1c. These results verify the presence of laccase in copper alginate beads.

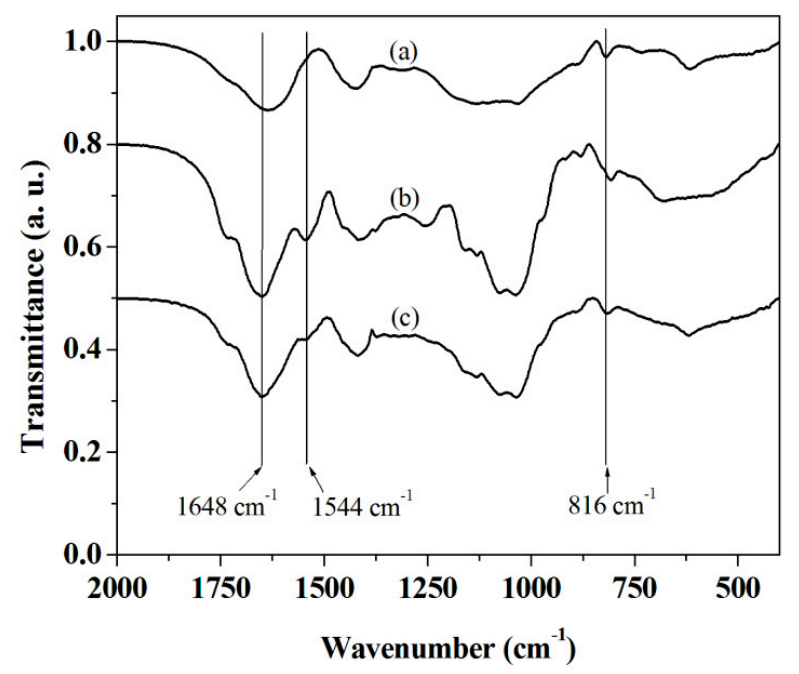

Figure 1. FTIR spectra of copper alginate beads (a), laccase (b) and copper alginate beads loaded with laccase (c).

\subsection{The Effect of Alginate Concentration}

The different Na-alginate concentrations (1.0-3.0 w/v\%) were used to screen the optimal specific activity and immobilization yield of entrapped laccase when using copper alginate beads as a carrier. 
As can be seen from Figure 2, the specific activities of entrapped laccase gradually decrease with the increasing alginate concentration. Generally speaking, the pore size of alginate beads decreases with the increase of Na-alginate concentration [33]. In this work, a higher concentration of Na-alginate solution leads to the presence of copper alginate beads with smaller pore sizes, which impedes the diffusion of ABTS and, thus, decreases the specific activity of entrapped laccase. In addition, it is demonstrated that the maximum immobilization yield can be seen when $1.5(w / v \%)$ of Na-alginate solution is used, and that a lower immobilization yield is observed with the further increase or decrease of Na-alginate concentration. The copper alginate beads with large pore sizes can be obtained as a low concentration of $\mathrm{Na}$-alginate solution is employed. The larger pore size of copper alginate beads causes the leakage of laccase and reduces the immobilization yield accordingly. When a high concentration of Na-alginate solution is used, the outermost part of the beads is completely complexed during the maturation [34]. As a result, the strongly complexed alginate seals the beads' pores and then partially blocks the diffusion of laccase toward the interior of the beads, causing the decrease of the immobilization yield. For obtaining the best immobilization yield (92\%) and good specific activity $(635.0 \mu \mathrm{mol} / \mathrm{mg} / \mathrm{min}), 1.5(w / v \%)$ of Na-alginate solution was chosen as the optimal concentration for subsequent investigations.

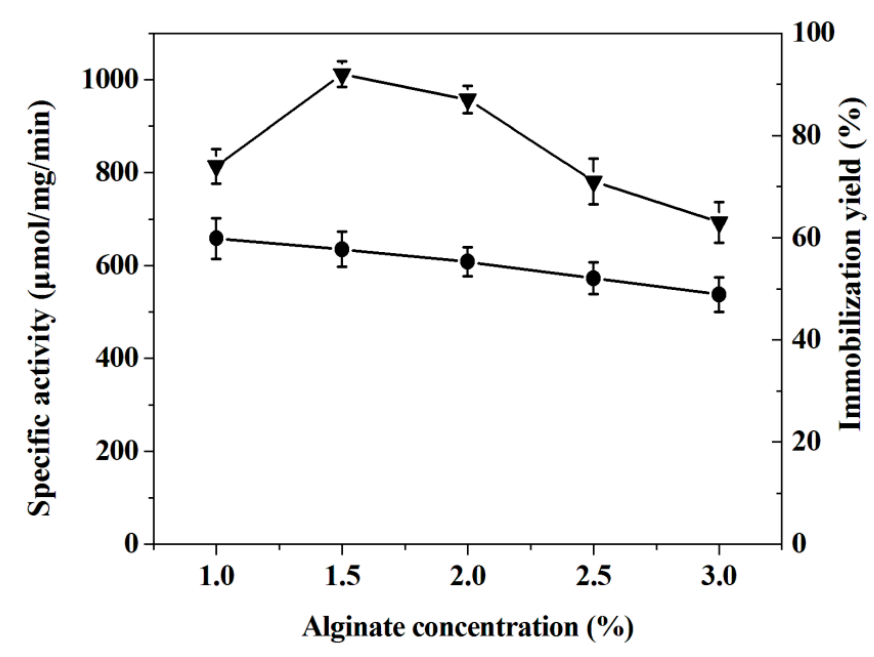

Figure 2. The effect of alginate concentration on specific activity $(\bullet)$ and immobilization yield $(\boldsymbol{\nabla})$ of laccase entrapped by protocol I.

\section{4. $\mathrm{pH}$ Stability}

It is well known that the state of ionization and dissociation of enzymes is most probably altered during the immobilization procedure [35]. Thus, $\mathrm{pH}$ stabilities of entrapped or free laccase were surveyed by first immersing them in buffers of different $\mathrm{pH}$ in the range of $2.2-8.0$ for $4 \mathrm{~h}$ at $25^{\circ} \mathrm{C}$, followed by activity estimation at $\mathrm{pH} 4.6$.

The laccase entrapped into Cu-alginate beads exhibits $87.6 \%$ and $91.3 \%$ of its original activity after four hours of incubation at $\mathrm{pH} 2.2$ and 8.0, respectively (Figure 3). The free laccase maintains $9.5 \%$ of its original activity at $\mathrm{pH} 2.2$ and $23.2 \%$ of its original activity at $\mathrm{pH} 8.0$ (Figure 3 ). This result demonstrates that entrapped laccase is more stable than free laccase, and that the entrapment procedure improves the laccase stability over a broader $\mathrm{pH}$ range, which is consistent with other investigators' results $[36,37]$. 


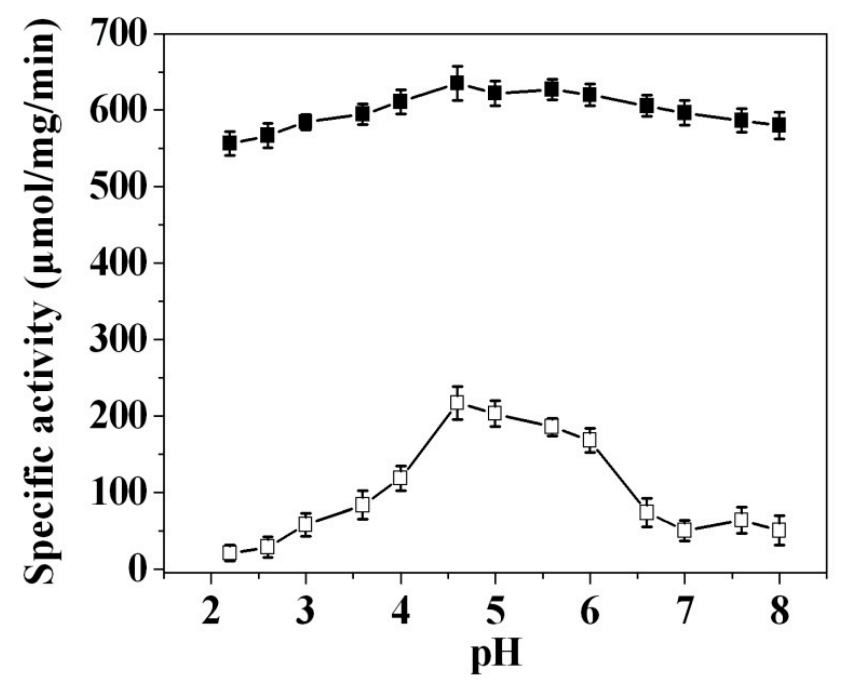

Figure 3. pH stability of laccase entrapped by protocol I ( $\square)$ and free laccase ( $\square$ ).

\subsection{Thermal Stability}

Thermal stability is one of the important criteria for industrial applications of laccase [38]. The heat inactivation studies were carried out to evaluate the effect of $\mathrm{Cu}$-alginate entrapment on the thermal stability of laccase. The entrapped and free laccase were incubated at different temperatures $\left(20-60{ }^{\circ} \mathrm{C}\right)$ for four hours and subsequently assayed for residual activity. As can be seen in Figure 4, after four hours of incubation, the entrapped and free laccase show the maximum specific activity at $40{ }^{\circ} \mathrm{C}$ and present the decreasing trend of specific activity with the further increase or decrease of the temperature in the range of $20-60^{\circ} \mathrm{C}$. The specific activity of entrapped laccase decreases at a slower rate than that of the free one at higher temperature $\left(40-60^{\circ} \mathrm{C}\right)$. The results show the thermal stability of laccase is substantially enhanced at higher temperatures. The improved thermal stability of laccase may be attributed to the protective effect provided by the net in $\mathrm{Cu}$-alginate beads. Such protective effect preserves the tertiary structure of laccase and protects laccase from disassembling the active center caused by the diminution of non-covalent forces at higher temperatures [39].

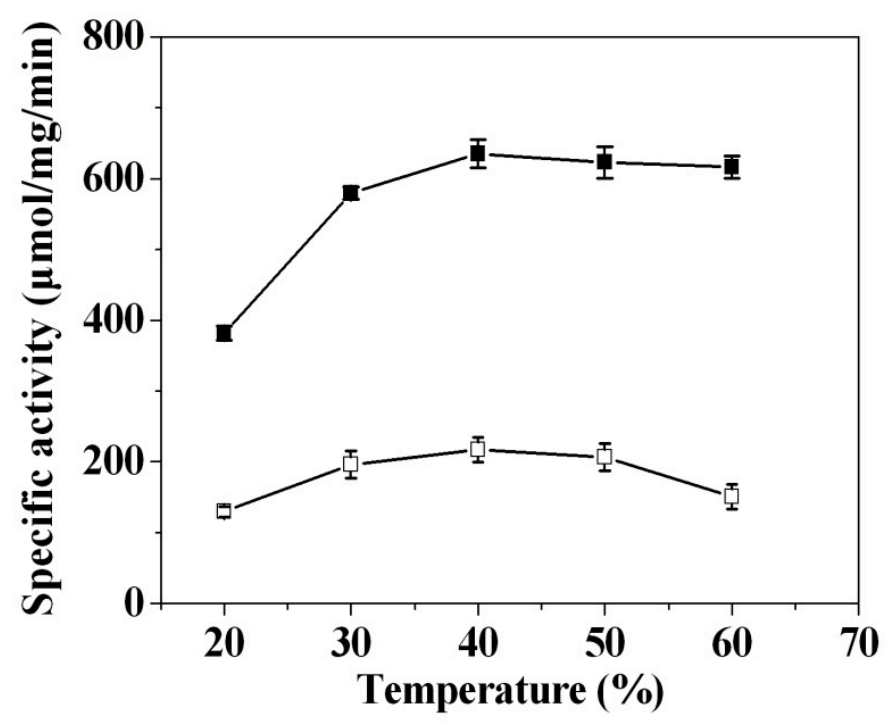

Figure 4. Temperature stability of laccase entrapped by protocol I ( $\square$ ) and free laccase ( $\square$ ). 


\subsection{Degradation of 2,4-Dichlorophenol}

In this work, the entrapped laccase was employed to degrade 2,4-dichlorophenol to determine its potential value for treating the phenol wastewater. It is noted that, after 10 hours of reaction time, the entrapped laccase presents a 2.4-fold increase in the degradation rate compared to that of the free laccase (Figure 5). The significant increase in the degradation rate shall be attributed to the activation of $\mathrm{Cu}^{2+}$ ions followed by the active conformation confinement produced by the net of $\mathrm{Cu}$-alginate beads for the entrapped laccase $[26,27]$.

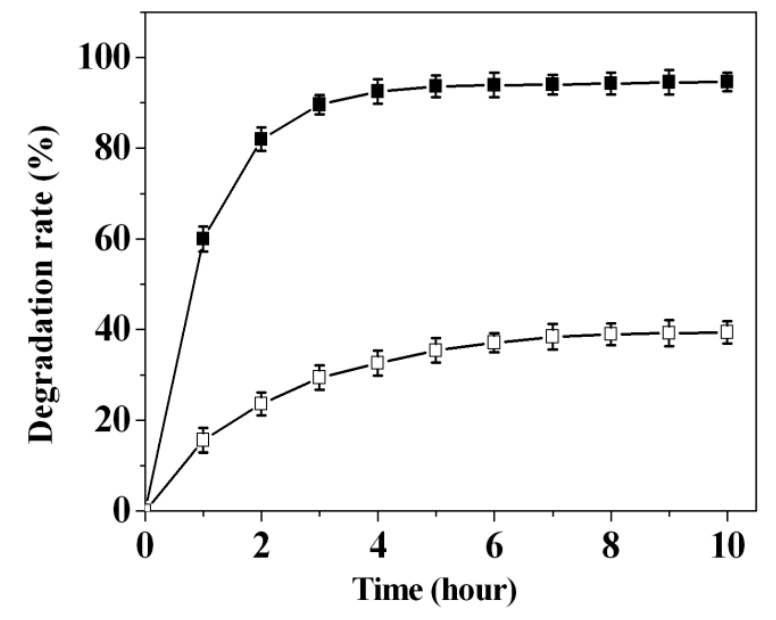

Figure 5. 2,4-DCP degradation rate using entrapped laccase ( $\square$ ) and free laccase ( $\square$ ).

\subsection{Reusability}

In industrial applications, the reusability of immobilized laccase is a key factor for its cost-effective use [40]. Hence, the reusability of the entrapped laccase was studied for the degradation of 2,4-dichlorophenol during continuous batch operation and the experimental data verifies that the degradation rate of entrapped laccase gradually decreases from $94.6 \%$ to $80.4 \%$ during ten reaction cycles (Figure 6). The experimental results demonstrate that the entrapped laccase possesses the perfect operational stability during continuous batch operation. The enhanced degradation rate and good operational stability benefit the removal of 2,4-dichlorophenol from phenol wastewater in practical applications.

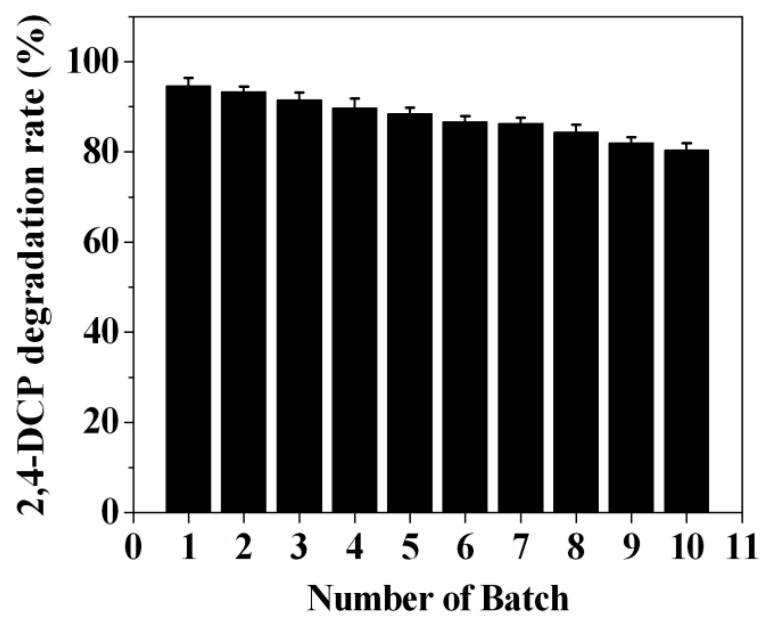

Figure 6. Reusability of entrapped laccase. 


\section{Materials and Methods}

\subsection{Materials}

Laccase from Trametes versicolor was obtained from Sigma-Aldrich (St. Louis, MO, USA). The 2,2'-azino-bis (3-ethylbenzothiazoline-6-sulfonic acid) (ABTS) and 2,4-dichlorophenol (2,4-DCP) was purchased from Sigma-Aldrich (St. Louis, MO, USA). KBr (spectral grade) was obtained from BDH Co. (Poole, UK). All other chemicals and reagents were of analytical grade. All aqueous solutions were prepared with Milli-Q water.

\subsection{Purification of Laccase}

The suitable amount of laccase powder was dissolved in $15 \mathrm{mM}$ sodium acetate ( $\mathrm{pH} 5.0$ ). Then, the crude laccase solution was applied to an anion-exchange (DEAE) column, which was equilibrated with $15 \mathrm{mM}$ sodium acetate ( $\mathrm{pH}$ 5.0). The laccase fraction was obtained by elution with 0.1 to $0.15 \mathrm{M} \mathrm{NaCl}$ through an anion-exchange (DEAE) column. Laccase containing fractions were pooled and concentrated. The concentrated laccase was dialyzed against $\mathrm{Na}_{2} \mathrm{HPO}_{4}$-citric acid buffer ( $\mathrm{pH}$ 4.6), and then lyophilized. Eventually, the lyophilized sample was stored at $-20{ }^{\circ} \mathrm{C}$ until further use. SDS-PAGE (12\%) was carried out to assess the purity of the purified laccase. The purified laccase produced one band on an SDS-PAGE gel at a molecular mass of approximately $66.3 \mathrm{kDa}$. $\mathrm{Na}_{2} \mathrm{HPO}_{4}$ (26.55 g) and citric acid (22.38 g) was dissolved in $2 \mathrm{~L}$ deionized water to prepare $\mathrm{Na}_{2} \mathrm{HPO}_{4}$-citric acid buffer (pH 4.6).

\subsection{Entrapment of Laccase with Different Protocols}

Protocol I: Ten milliliters of sonicated sodium alginate solution $(1.0 \%, w / v)$ was dropped into a pre-cooled $10 \mathrm{~mL} \mathrm{CuCl}_{2}$ solution $(0.2 \mathrm{M})$ containing laccase $(2 \mathrm{mg} / \mathrm{mL})$ by using of a syringe (internal diameter $0.5 \mathrm{~mm}$ ) with continuous gentle hand swirling. The diameter of enzyme entrapped $\mathrm{Cu}$-alginate beads is approx. $2.5 \mathrm{~mm}$. The beads were allowed to harden at $4{ }^{\circ} \mathrm{C}$ in the $\mathrm{CuCl}_{2}$ solution for $4 \mathrm{~h}$. The beads were filtered off, washed with water and stored at $4{ }^{\circ} \mathrm{C}$ until use.

Protocol II: Twenty milligrams of purified laccase was dissolved into $10 \mathrm{~mL}$ sonicated sodium alginate solution (1.0\%). Then, the alginate solution containing laccase was added to $10 \mathrm{~mL} \mathrm{of} \mathrm{CuCl}_{2}$ solution $(0.2 \mathrm{M})$ by a syringe. The other operations were performed according to protocol I.

Protocol III: The $\mathrm{CuCl}_{2}$ solution $(0.2 \mathrm{M})$ was replaced by $\mathrm{CaCl}_{2}$ solution $(0.2 \mathrm{M})$. The other operations were executed according to protocol I.

Protocol IV: The $\mathrm{CuCl}_{2}$ solution $(0.2 \mathrm{M})$ was replaced by $\mathrm{CaCl}_{2}$ solution $(0.2 \mathrm{M})$. The other operations were carried out according to protocol II.

\subsection{Calculation of Specific Activity, Immobilization Yield}

\subsubsection{Immobilization Yield}

The protein concentration in the supernatant was quantified using the Bradford protein assay with BSA as a standard [41]. The immobilization yield was calculated as follows:

$$
Y=\left(\mathrm{W}_{1}-\mathrm{W}_{2}\right) \times 100 / \mathrm{W}_{1}
$$

where $Y=$ Immobilization yield (\%), $\mathrm{W}_{1}=$ the total amount of laccase added to immobilization system, and $W_{2}=$ the total amount of laccase recovered from the pooled supernatant and washing fractions.

\subsubsection{Specific Activity}

The specific activity of free and entrapped laccase was determined by using ABTS as the substrate [42]. The reaction mixture contained $3 \mathrm{mM}$ ABTS, $\mathrm{Na}_{2} \mathrm{HPO}_{4}$-citric acid buffer ( $\mathrm{pH} 4.6$ ), and a suitable amount of free and entrapped laccase. The amount of free and entrapped laccase was chosen 
to make the absorbance of the reaction product within the linear range of the spectrophotometer used in the experiment (UV-2550, Shimadzu, Kyoto, Japan). The reaction mixture was incubated in a water bath at $40{ }^{\circ} \mathrm{C}$ for $3 \mathrm{~min}$. Then, the reaction mixture was stopped by cooling in an ice bath for $3 \mathrm{~min}$. For entrapped laccase, the reaction mixture was filtrated by a membrane filter $(0.22-\mu \mathrm{m}$ pore size) to obtain the supernatant used for the activity assay. Oxidation of ABTS was measured as the absorbance increase at $420 \mathrm{~nm}\left(\varepsilon_{420}=36,000 \mathrm{M}^{-1} \mathrm{~cm}^{-1}\right)$. The specific activity $\left(\mu \mathrm{mol} \mathrm{min} \mathrm{mg}^{-1}\right)$ was defined as the amount of ABTS oxidized per minute per milligram of both free and entrapped laccase.

\subsection{FTIR}

The FTIR spectrums of the samples were surveyed using a spectrophotometer (Nicolet 5700 , Thermo Electron Corporation, Waltham, MA, USA) with a resolution of $4 \mathrm{~cm}^{-1}$ via the the $\mathrm{KBr}$ method.

\subsection{The Effect of Alginate Concentration}

Varying concentrations of sodium alginate $(1.0-3.0 \%(w / v))$ were used during the entrapment of laccase. The specific activities and immobilized yields were assayed according to the description in Sections 3.4.1 and 3.4.2.

\section{7. $p H$ Stability}

The $\mathrm{pH}$ stability of entrapped or free laccase was determined using $\mathrm{Na}_{2} \mathrm{HPO}_{4}$-citric acid buffers ranging in $\mathrm{pH}$ from 2.2 to 8.0 at $40{ }^{\circ} \mathrm{C}$. The specific activity was determined according to the assay in Section 3.4.2.

\subsection{Thermal Stability}

Thermal stability of entrapped or free laccase was evaluated under different temperatures $\left(20-60^{\circ} \mathrm{C}\right)$ at $\mathrm{pH}$ 4.6. The specific activity was determined according to the assay in Section 3.4.2.

\subsection{Degradation of 2,4-Dichlorophenol}

The desired amount of entrapped laccase or free laccase was added to $200 \mathrm{~mL}$ of 2,4-DCP solution (10 mg/L, prepared in $\mathrm{pH} 4.6 \mathrm{Na}_{2} \mathrm{HPO}_{4}$-citric acid buffer). Then, the reaction system was placed at $40{ }^{\circ} \mathrm{C}$ with slow stirring for 10 hours. Samples were withdrawn at one-hour intervals followed by centrifugation at $3500 \times \mathrm{g}$ for $1 \mathrm{~min}$. The concentrations of 2,4-DCP in supernatant were measured by a colorimetric method [43]. In brief, $10 \mathrm{~mL}$ of the supernatant was added to $40 \mathrm{~mL}$ of deionized water, followed by the addition of $1.25 \mathrm{~mL}$ of $\mathrm{NH}_{3} \cdot \mathrm{H}_{2} \mathrm{O}\left(0.5 \mathrm{~mol} \mathrm{~L}^{-1}\right)$. After the $\mathrm{pH}$ of the diluted supernatant was adjusted to 7.9 by $\mathrm{H}_{3} \mathrm{PO}_{4}-\mathrm{Na}_{2} \mathrm{HPO}_{4}$ buffer ( $\mathrm{pH}$ 6.7), $0.1 \mathrm{~mL} 4$-aminoantipyrine solution $(20 \mathrm{~g} / \mathrm{L}$ ) and $0.1 \mathrm{~mL}$ ferricyanide solution $\left(24.3 \mathrm{mmol} \mathrm{K}_{3} \mathrm{Fe}(\mathrm{CN})_{6}\right.$ in $\left.100 \mathrm{~mL} \mathrm{H}_{2} \mathrm{O}\right)$ were added with stirring. The mixture was then incubated at room temperature with stirring and kept for $15 \mathrm{~min}$. The absorbance of the assay system at $510 \mathrm{~nm}$ was measured by UV-visible spectrophotometer (Shimadzu UV-2550, Shimadzu, Kyoto, Japan). The standard curve was plotted as the absorbance at $510 \mathrm{~nm}$ versus the concentration of 2,4-DCP to determine the 2,4-DCP concentration in the assay system. The degradation rate (DR) referred to the percentage of degraded 2,4-DCP accounting for the initial system.

\subsection{Reusability}

The Cu-alginate beads loaded with laccase were used for successive batch treatments of 2,4-DCP. The reaction mixture containing $200 \mathrm{~mL}$ of 2,4-DCP $(10 \mathrm{mg} / \mathrm{L})$ and a suitable amount of entrapped laccase was incubated at $40{ }^{\circ} \mathrm{C}$ with slow stirring for 10 hours. Then, the reaction mixture was centrifuged. The degradation rate of 2,4-DCP in supernatant was determined according to the method in Section 3.9. The recovered $\mathrm{Cu}$-alginate beads were washed three times with distilled water to remove any residual substrate or product. Washed $\mathrm{Cu}$-alginate beads were used in the next cycle under otherwise equivalent conditions. 


\subsection{Statistical Analysis}

The data expressed in various studies was plotted using Sigma Plot-9 and expressed as standard error $( \pm)$. Each value represents the mean for three independent experiments performed in duplicate, with average standard deviation $<5 \%$.

\section{Conclusions}

In summary, laccase from Trametes versicolor was pretreated by copper ion solution followed by the copper alginate entrapment. The entrapped laccase presents excellent $\mathrm{pH}$ stability and thermal stability when using ABTS as model substrate. During the degradation of 2,4-dichlorophenol, the entrapped laccase shows good operational stability. Furthermore, the entrapped laccase has an increase in specific activity of $130 \%$ compared with free enzyme supplemented by $\mathrm{CuCl}_{2}$ in the oxidation of ABTS. The degradation rate of free laccase for removing 2,4-dichlorophenol is increased by a factor of 2.4 with the coupled effect of $\mathrm{Cu}^{2+}$ ions activation and copper alginate entrapment. The new entrapment protocol provides a promising catalyst for the bioremediation.

Author Contributions: S.Z. performed the entrapment of the laccase in copper alginate and the determination of the specific activities, and wrote the paper; Z.W. (Zhuofu Wu) contributed to the degradation assay of 2,4-dichlorophenol and revised the paper; and G.C. and Z.W. (Zhi Wang) conceived and designed the experiments.

Acknowledgments: The authors are grateful for the financial support from the Fund of Basic Scientific Research from Jilin University (for Constructing the Scientific and Technological Platform, 2017), the Jilin Province Innovation Platform of Straw Comprehensive Utilization Technology (Technology and Innovation Platform of Colleges and Universities of Jilin Province (2014) C-1)), the 13th Five-Year scientific research Planning Project of the Education Department of Jilin Province (JJKH20170305KJ), and the PhD Scientific Research Start-up Fund Project of Jilin Agricultural University (201607).

Conflicts of Interest: The authors declare no conflict of interest.

\section{References}

1. Tarasi, R.; Alipour, M.; Gorgannezhad, L.; Imanparast, S.; Yousefi-Ahmadipour, A.; Ramezani, A.; Ganjali, M.R.; Shafiee, A.; Faramarzi, M.A.; Khoobi, M. Laccase immobilization onto magnetic $\beta$-cyclodextrin-modified chitosan: Improved enzyme stability and efficient performance for phenolic compounds elimination. Macromol. Res. 2018, 26, 1-8. [CrossRef]

2. Cusola, O.; Valls, C.; Vidal, T.; Roncero, M.B. Using electrochemical methods to study the kinetics of laccase-catalyzed oxidation of phenols. Ind. Eng. Chem. Res. 2018, 57, 2434-2439. [CrossRef]

3. Yesilada, O.; Birhanli, E.; Geckil, H. Bioremediation and decolorization of textile dyes by white rot fungi and laccase enzymes. In Mycoremediation and Environmental Sustainability; Springer: Cham, Switzerland, 2018; Volume 7, pp. 121-153.

4. Agrawal, P.K.; Shrivastava, R.; Verma, J. Bioremediation approaches for degradation and detoxification of polycyclic aromatic hydrocarbons. In Emerging and Eco-Friendly Approaches for Waste Management; Springer: Singapore, 2019; Volume 6, pp. 99-119.

5. Rocha-Martín, J.; Martínez-Bernal, C.; Zamorano, L.S.; Reyes-Sosa, F.M.; Díez García, B. Inhibition of enzymatic hydrolysis of pretreated corn stover and sugar cane straw by laccases. Process Biochem. 2018, 67, 88-91. [CrossRef]

6. $\mathrm{Xu}, \mathrm{F}$. Oxidation of phenols, anilines, and benzenethiols by fungal laccases: Correlation between activity and redox potentials as well as halide inhibition. Biochemistry 1996, 35, 7608-7614. [CrossRef] [PubMed]

7. Nunes, C.S.; Kunamneni, A. Laccases-properties and applications. In Enzymes in Human and Animal Nutrition; Elsevier: Chennai, India, 2018; Volume 7, pp. 133-161.

8. Brugnari, T.; Pereira, M.G.; Bubna, G.A.; de Freitas, E.N.; Contato, A.G.; Corrêa, R.C.G.; Castoldi, R.; de Souza, C.G.M.; de Moraes, M.d.L.T.; Bracht, A. A highly reusable MANAE-agarose-immobilized Pleurotus ostreatus laccase for degradation of bisphenol A. Sci. Total Environ. 2018, 634, 1346-1351. [CrossRef] [PubMed]

9. Amin, R.; Khorshidi, A.; Shojaei, A.F.; Rezaei, S.; Faramarzi, M.A. Immobilization of laccase on modified $\mathrm{Fe}_{3} \mathrm{O}_{4} @ \mathrm{SiO}_{2} @$ kit-6 magnetite nanoparticles for enhanced delignification of olive pomace bio-waste. Int. J. Biol. Macromol. 2018, 114, 106-113. [CrossRef] [PubMed] 
10. Míguez, N.; Gimeno-Pérez, M.; Fernández-Polo, D.; Cervantes, F.; Ballesteros, A.; Fernández-Lobato, M.; Ribeiro, M.; Plou, F. Immobilization of the $\beta$-fructofuranosidase from Xanthophyllomyces Dendrorhous by entrapment in polyvinyl alcohol and its application to neo-fructooligosaccharides production. Catalysts 2018, 8, 201-212. [CrossRef]

11. Petrovičová, T.; Markošová, K.; Hegyi, Z.; Smonou, I.; Rosenberg, M.; Rebroš, M. Co-immobilization of ketoreductase and glucose dehydrogenase. Catalysts 2018, 8, 168-176. [CrossRef]

12. Facchini, F.; Pereira, M.; Vici, A.; Filice, M.; Pessela, B.; Guisan, J.; Fernandez-Lorente, G.; Polizeli, M. Immobilization effects on the catalytic properties of two Fusarium Verticillioides lipases: Stability, hydrolysis, transesterification and enantioselectivity improvement. Catalysts 2018, 8, 84-100. [CrossRef]

13. Rogalski, J.; Dawidowicz, A.; Jóźwik, E.; Leonowicz, A. Immobilization of laccase from cerrena unicolor on controlled porosity glass. J. Mol. Catal. B: Enzym. 1999, 6, 29-39. [CrossRef]

14. Dodor, D.E.; Hwang, H.-M.; Ekunwe, S.I. Oxidation of anthracene and benzo[a]pyrene by immobilized laccase from trametes versicolor. Enzym. Microb. Technol. 2004, 35, 210-217. [CrossRef]

15. Hu, X.; Zhao, X.; Hwang, H.-M. Comparative study of immobilized Trametes versicolor laccase on nanoparticles and kaolinite. Chemosphere 2007, 66, 1618-1626. [CrossRef] [PubMed]

16. Huber, D.; Pellis, A.; Daxbacher, A.; Nyanhongo, G.S.; Guebitz, G.M. Polymerization of various lignins via immobilized myceliophthora thermophila laccase (mtl). Polymers 2016, 8, 280-289. [CrossRef]

17. Huber, D.; Bleymaier, K.; Pellis, A.; Vielnascher, R.; Daxbacher, A.; Greimel, K.J.; Guebitz, G.M. Laccase catalyzed elimination of morphine from aqueous systems. New Biotechnol. 2018, 42, 19-25. [CrossRef] [PubMed]

18. Daâssi, D.; Rodríguez-Couto, S.; Nasri, M.; Mechichi, T. Biodegradation of textile dyes by immobilized laccase from Coriolopsis Gallica into Ca-alginate beads. Int. Biodeterior. Biodegrad. 2014, 90, 71-78. [CrossRef]

19. Shojaat, R.; Saadatjoo, N.; Karimi, A.; Aber, S. Simultaneous adsorption-degradation of organic dyes using $\mathrm{MnFe}_{2} \mathrm{O}_{4}$ /calcium alginate nano-composites coupled with gox and laccase. J. Environ. Chem. Eng. 2016, 4, 1722-1730. [CrossRef]

20. Ouwerx, C.; Velings, N.; Mestdagh, M.; Axelos, M. Physico-chemical properties and rheology of alginate gel beads formed with various divalent cations. Polym. Gels Netw. 1998, 6, 393-408. [CrossRef]

21. Singh, L.; Pavankumar, A.R.; Lakshmanan, R.; Rajarao, G.K. Effective removal of cu2+ ions from aqueous medium using alginate as biosorbent. Ecol. Eng. 2012, 38, 119-124. [CrossRef]

22. Phetsom, J.; Khammuang, S.; Suwannawong, P.; Sarnthima, R. Copper-alginate encapsulation of crude laccase from Lentinus Polychrous Lev. and their effectiveness in synthetic dyes decolorizations. J. Biol. Sci. 2009, 9, 573-583.

23. Teerapatsakul, C.; Bucke, C.; Parra, R.; Keshavarz, T.; Chitradon, L. Dye decolorisation by laccase entrapped in copper alginate. World J. Microbiol. Biotechnol. 2008, 24, 1367-1374. [CrossRef]

24. Cao, L. Unconventional enzyme immobilization. In Carrier-Bound Immobilized Enzymes; Wiley-VCH Verlag GmbH \& Co. KGaA: Delft, The Netherlands, 2006; Volume 6, pp. 449-549.

25. Rodrigues, R.C.; Ortiz, C.; Berenguer-Murcia, A.; Torres, R.; Fernandez-Lafuente, R. Modifying enzyme activity and selectivity by immobilization. Chem. Soc. Rev. 2013, 42, 6290-6307. [CrossRef] [PubMed]

26. Minton, A.P. The influence of macromolecular crowding and macromolecular confinement on biochemical reactions in physiological media. J. Biol. Chem. 2001, 276, 10577-10580. [CrossRef] [PubMed]

27. Zhou, H.-X.; Dill, K.A. Stabilization of proteins in confined spaces. Biochemistry 2001, 40, 11289-11293. [CrossRef] [PubMed]

28. Wang, L.-B.; Wang, Y.-C.; He, R.; Zhuang, A.; Wang, X.; Zeng, J.; Hou, J. A new nanobiocatalytic system based on allosteric effect with dramatically enhanced enzymatic performance. J. Am. Chem. Soc. 2013, 135, 1272-1275. [CrossRef] [PubMed]

29. Ge, J.; Lei, J.; Zare, R.N. Protein-inorganic hybrid nanoflowers. Nat. Nanotechnol. 2012, 7, 428. [CrossRef] [PubMed]

30. Papageorgiou, S.K.; Kouvelos, E.P.; Favvas, E.P.; Sapalidis, A.A.; Romanos, G.E.; Katsaros, F.K. Metal-carboxylate interactions in metal-alginate complexes studied with FTIR spectroscopy. Carbohydr. Res. 2010, 345, 469-473. [CrossRef] [PubMed]

31. Yang, W.-J.; Griffiths, P.R.; Byler, D.M.; Susi, H. Protein conformation by infrared spectroscopy: Resolution enhancement by fourier self-deconvolution. Appl. Spectrosc. 1985, 39, 282-287. [CrossRef] 
32. Krimm, S.; Bandekar, J. Vibrational spectroscopy and conformation of peptides, polypeptides, and proteins. Adv. Protein Chem. 1986, 38, 181-364. [PubMed]

33. Klein, J.; Stock, J.; Vorlop, K.D. Pore size and properties of spherical Ca-alginate biocatalysts. European J. Appl. Microbiol. Biotechnol. 1983, 18, 86-91. [CrossRef]

34. Velings, N.M.; Mestdagh, M.M. Physico-chemical properties of alginate gel beads. Polym. Gels Netw. 1995, 3 , 311-330. [CrossRef]

35. Lee, C.-H.; Lin, T.-S.; Mou, C.-Y. Mesoporous materials for encapsulating enzymes. Nano Today 2009, 4, 165-179. [CrossRef]

36. Berrio, J.; Plou, F.J.; Ballesteros, A.; Martínez, Á.T.; Martínez, M.J. Immobilization of Pycnoporus coccineus laccase on Eupergit C: Stabilization and treatment of olive oil mill wastewaters. Biocatal. Biotransform. 2007, 25, 130-134. [CrossRef]

37. Zhang, S.; Gao, E.; Xia, L. Dechlorination of dichlorophenol in waste water by immobilized laccase. J. Chem. Soc. Perkin Trans. 2 2006, 57, 359-362.

38. Sanlıer, S.H.; Gider, S.; Köprülü, A. Immobilization of laccase for biotechnology applications. Artif. Cell Nano. Bio. 2013, 41, 259-263. [CrossRef] [PubMed]

39. Seckler, R.; Jaenicke, R. Protein folding and protein refolding. FASEB J. 1992, 6, 2545-2552. [CrossRef] [PubMed]

40. Tran, D.N.; Balkus Jr, K.J. Perspective of recent progress in immobilization of enzymes. ACS Catal. 2011, 1, 956-968. [CrossRef]

41. Bradford, M.M. A rapid and sensitive method for the quantitation of microgram quantities of protein utilizing the principle of protein-dye binding. Anal. Biochem. 1976, 72, 248-254. [CrossRef]

42. Wolfenden, B.S.; Willson, R.L. Radical-cations as reference chromogens in kinetic studies of one-electron transfer reactions: Pulse radiolysis studies of 2, 2'-azinobis-(3-ethylbenzthiazoline-6-sulphonate). J. Chem. Soc. Perkin Trans. 2 1982, 0, 805-812. [CrossRef]

43. Yang, J.; Huang, Y.; Yang, Y.; Yuan, H.; Liu, X. Cagelike mesoporous silica encapsulated with microcapsules for immobilized laccase and 2, 4-DCP degradation. J. Environ. Sci. 2015, 38, 52-62. [CrossRef] [PubMed]

(C) 2018 by the authors. Licensee MDPI, Basel, Switzerland. This article is an open access article distributed under the terms and conditions of the Creative Commons Attribution (CC BY) license (http:/ / creativecommons.org/licenses/by/4.0/). 